\title{
Interleukin-4, Oxidative Stress, Vascular Inflammation and Atherosclerosis
}

\author{
Yong Woo LeE ${ }^{1,2, *}$, Paul H. KIM ${ }^{1}$, Won Hee LeE ${ }^{2}$, and Anjali A. HIRANI ${ }^{2}$ \\ ${ }^{1}$ Department of Biomedical Sciences and Pathobiology, ${ }^{2}$ School of Biomedical Engineering and Sciences, \\ Virginia Polytechnic Institute and State University (Virginia Tech), Blacksburg, VA 24061, USA
}

(Received March 30, 2010; Accepted April 14, 2010)

\begin{abstract}
The pro-oxidative and pro-inflammatory pathways in vascular endothelium have been implicated in the initiation and progression of atherosclerosis. In fact, inflammatory responses in vascular endothelium are primarily regulated through oxidative stress-mediated signaling pathways leading to overexpression of pro-inflammatory mediators. Enhanced expression of cytokines, chemokines and adhesion molecules in endothelial cells and their close interactions facilitate recruiting and adhering blood leukocytes to vessel wall, and subsequently stimulate transendothelial migration, which are thought to be critical early pathologic events in atherogenesis. Although interleukin-4 (IL-4) was traditionally considered as an anti-inflammatory cytokine, recent in vitro and in vivo studies have provided robust evidence that IL-4 exerts pro-inflammatory effects on vascular endothelium and may play a critical role in the development of atherosclerosis. The cellular and molecular mechanisms responsible for IL-4-induced atherosclerosis, however, remain largely unknown. The present review focuses on the distinct sources of IL-4-mediated reactive oxygen species (ROS) generation as well as the pivotal role of ROS in IL-4-induced vascular inflammation. These studies will provide novel insights into a clear delineation of the oxidative mechanisms of IL-4-mediated stimulation of vascular inflammation and subsequent development of atherosclerosis. It will also contribute to novel therapeutic approaches for atherosclerosis specifically targeted against pro-oxidative and pro-inflammatory pathways in vascular endothelium.
\end{abstract}

Keywords: IL-4, Reactive oxygen species, Inflammation, Vascular endothelium, Atherosclerosis

\section{IL-4 AND ATHEROSCLEROSIS}

Cardiovascular disease (CVD) including atherosclerosis is one of the leading causes of illness and death worldwide. In the United States, an estimated 81,100,000 American adults have one or more types of CVD and the estimated cost of CVD for 2010 is $\$ 503.2$ billion (American Heart Association Statistics Committee and Stroke Statistics Subcommittee, 2010). Although the exact cause of this disease remains unsolved, the pro-oxidative and pro-inflammatory vascular environments are fundamental contributors to the initiation and progression of CVD (Hennig and Chow, 1988; Ylä-Herttuala, 1992; Ross, 1993; Hennig

${ }^{*}$ Corresponding author

Tel: +1-540-231-8484

E-mail: ywlee@vt.edu et al., 1996; Bouloumie et al., 1999; Heitzer et al., 2001; Sorescu et al., 2002; Guzik et al., 2006; Thomas et al., 2008).

Although the contribution of T-helper 1 (Th1) and Thelper 2 (Th2) cell responses to the development of atherosclerosis remains unclear, pro-inflammatory cytokines secreted by Th1 cells (Th1 cytokines) have been implicated in atherogenesis. It is commonly believed that interferon- $\gamma$ (INF- $\gamma$ ), a typical Th1 cytokine, exerts pro-inflammatory and pro-atherogenic action (Tedgui and Mallat, 2006). However, the development of atherosclerosis was not completely abolished even though disruption of INF- $\gamma$ gene diminished the severity of this disease in low density lipoprotein receptor (LDLR)-deficient mice (Buono et al., 2003). These studies raise the possibility that other pathways may also contribute to the disease progression. Indeed, there is increasing evidence that Th2 cells might 
play a role while little is known concerning the possible contribution of Th2 cytokines to the vascular inflammation and atherosclerosis (Masinovsky et al., 1990; Paul, 1991; Rollins and Pober, 1991; Galéa et al., 1993; Rocken et al., 1996; Barks et al., 1997; Blease et al., 1998; Lee et al., 2001a; Lee et al., 2001b; King et al., 2002; Davenport and Tipping, 2003; Lee et al., 2003; Lee et al., 2004b; Lee and Hirani, 2006; Walch et al., 2006; Hong et al., 2008; Lee et al., 2010a; Lee et al., 2010b).

Interleukin-4 (IL-4) is a pleiotropic immunomodulatory cytokine secreted by Th2 cells (Th2 cytokines) and was traditionally considered as an anti-inflammatory cytokine (Paul, 1991; Rocken et al., 1996). A growing body of evidence, however, has indicated that IL-4 is a pro-inflammatory cytokine and plays a critical role in the progression of atherosclerosis. For example, IL-4 induces pro-inflammatory environments by overexpressing a number of inflammatory mediators in vascular endothelial cells (Rollins and Pober, 1991; Galéa et al., 1993; Lee et al., 2001a; Lee et al., 2001b; Lee et al., 2003; Lee et al., 2004b; Lee and Hirani, 2006; Tedgui and Mallat, 2006; Walch et al., 2006; Huang et al., 2007; Hong et al., 2008; Huang et al., 2009; Lee et al., 2010a; Lee et al., 2010b). In addition, IL-4 synergistically increases interleukin-1 $\beta$ (IL-1 $\beta)$-, tumor necrosis factor- $\alpha$ (TNF- $\alpha$ )-, or lipopolysaccharide (LPS)-induced vascular cell adhesion molecule-1 (VCAM-1) expression in vascular endothelium (Barks et al., 1997; Blease et al., 1998). Additionally, IL-4 increases endothelial cell turnover by accelerated apoptosis, the event which may alter the function of the vascular endothelium and thereby promote atherogenesis (Lee et al., 2000). The pro-atherogenic effects of IL-4 have also been investigated in animal models of atherosclerosis. King et al. (2002) demonstrated that transplantation of bone marrow stem cells collected from IL-4-deficient mice led to decreased atherosclerotic lesion formation in LDLR-deficient mice. Furthermore, a significant reduction in atherosclerotic plaque area was observed in IL-4-deficient/ApoE-deficient mice compared to ApoE-deficient mice (Davenport and Tipping, 2003). These findings suggest that there may be potential, novel pathways by which IL-4 exerts its pro-atherogenic effects. The cellular and molecular mechanisms responsible for IL-4-induced atherosclerosis, however, remain largely unknown. Therefore, the present review specifically focuses on the oxidative mechanisms by which IL-4, a relatively unstudied cytokine, induces vascular inflammation that will provide insights to novel preventive and therapeutic approaches for atherosclerosis specifically targeted against pro-oxidative and pro-inflammatory pathways in vascular endothelium.

\section{IL-4 AND VASCULAR INFLAMMATION}

It is generally accepted that atherosclerosis is a chronic inflammatory disease of the vessel walls (Ross, 1999; Clark, 2002; Libby et al., 2002; Shishehbor and Bhatt, 2004; Marx and Grant, 2007). The development of inflammatory reactions in vascular endothelium is a normal defense mechanism in response to the blood vessel injuries. The physiological significance of such reactions is to maintain and repair normal structure and function of the vessel wall. Excessive inflammatory reactions, however, are associated with vascular pathophysiology such as progression of atherosclerotic plaque formation (Berliner et al., 1995; Toborek and Kaiser, 1999). Previous studies have demonstrated that inflammatory responses in vascular endothelium are primarily regulated through production of pro-inflammatory mediators (Ross, 1999; Lee et al., 2004a). In fact, enhanced expression of cytokines, chemokines and adhesion molecules in vascular endothelial cells and their close interactions facilitate recruiting and adhering blood leukocytes to vessel wall, and subsequently stimulate transendothelial migration, which can be considered an early atherogenic process (Davies et al., 1993; Reape and Groot, 1999; Tedgui and Mallat, 2006).

\section{Effect of IL-4 on IL-6 expression in vascular endothelium}

The crucial role for pro-inflammatory cytokines in the initiation and progression of atherosclerosis has been widely recognized. IL-1 $\beta$ and TNF- $\alpha$ are well known pro-atherogenic cytokines, and the pathophysiological roles of these pro-inflammatory cytokines in atherosclerosis have been extensively investigated both in vitro and in vivo (Kirii et al., 2003; Ohta et al., 2005; Tedgui and Mallat, 2006). In addition, interleukin-6 (IL-6) plays an important role in the mediation of inflammatory and immune responses initiated by infection or injury. Elevated expression levels of IL- 6 have been reported in patients with cardiovascular diseases including atherosclerosis (Ross, 1999; Ridker et al., 2000a; Ridker et al., 2000b; Libby et al., 2002; Cesari et al., 2003; Kishimoto, 2005). Both mRNA and protein expression of IL-6 have been detected in human atherosclerotic lesions (Kishikawa et al., 1993; Seino et al., 1994). IL-6 has also been found in the atherosclerotic plaques of ApoE-deficient mice aorta (Sukovich et al., 1998), and treatment of ApoE-deficient mice with exogenous IL-6 greatly exacerbated atherosclerotic lesion formation (Huber et al., 1999). Further, the underlying molecular and cellular mechanisms how IL-6 contributes to atherosclerosis have been reported. A number of in vivo and in vitro studies have shown that IL- 6 augments atherogenesis by perpetu- 
ating vascular inflammation through induction of endothelial activation/dysfunction and recruitment of inflammatory cells (Schuett et al., 2009). Srinivasan et al. (2004) demonstrated that IL-6 directly mediated glucose-stimulated monocyte adhesion to vascular endothelial cells. It was also found that IL- 6 was a direct mediator of T cell migration (Weissenbach et al., 2004). These studies strongly support the idea that overexpression of IL-6 in vascular endothelium plays a critical role in the initiation and progression of atherosclerosis.

The stimulatory effect of IL-4 on IL-6 expression in vascular endothelium has been documented. For example, Chen and Manning (1996) showed that treatment of human umbilical vein endothelial cells (HUVEC) with IL-4 resulted in a significant increase in the basal levels of IL-6 expression. In addition, several reports demonstrated that IL-4 synergistically amplified the TNF- $\alpha$-, IL-1 $\beta$ - or LPS-induced production of IL-6 in HUVEC (Colotta et al., 1992; Paleolog et al., 1992; Chen and Manning, 1996). We have also demonstrated that IL-4 significantly and dose-dependently up-regulates mRNA and protein expression of IL-6 in HUVEC (Lee et al., 2004b; Lee et al., 2006). Although HUVEC have been traditionally used, they may not be appropriate for in vitro model of atherosclerosis because they are endothelial cells isolated from vein. Therefore, we employed human aortic endothelial cells (HAEC), primarily isolated and purified from human aortas, to provide more physiologically and clinically relevant cell culture model of atherosclerosis research. Our recent data showing that IL-4 significantly induced the expression of IL-6 mRNA and enhanced IL-6 protein production appear to be the first to document the stimulatory effect of IL-4 on IL-6 expression in HAEC and mice (Lee et al., 2010a). The molecular basis for the induction of IL-6 by IL-4 in vascular endothelium, however, remains unclear and to be further investigated.

\section{Effect of IL-4 on MCP-1 expression in vascular endothe- lium}

The recruitment of blood leukocytes and their migration throughout vascular endothelium are thought to be critical early pathologic events in atherogenesis. These processes are directly facilitated by enhanced expression of pro-inflammatory chemokines and chemokine receptors from activated endothelial cells and leukocytes (Rollins, 1997; Gu et al., 1999; Bursill et al., 2004; Sheikine and Hansson, 2006; Braunersreuther et al., 2007). Monocyte chemoattractant protein-1 (MCP-1) is the best characterized member of the $\mathrm{CC}$ chemokine family and plays a key role in recruitment of monocytes into the arterial wall and transmigration into the subendothelial regions of the vessels. MCP-1 is expressed and released by various types of cells within the vessel wall, including endothelial cells and smooth muscle cells, in response to a number of extracellular stimuli such as cytokines and platelet-derived growth factor (Strieter et al., 1989; Rollins and Pober, 1991; Taubman et al., 1992; Wung et al., 1997; Bouloumie et al., 1999; Lee et al., 2003). A number of previous studies demonstrated the pivotal role of MCP-1 in the pathogenesis of atherosclerosis. Both MCP-1 mRNA and protein expression were detected in early atherosclerotic lesions (Nelken et al., 1991; Ylä-Herttuala et al., 1991; Takeya et al., 1993). Additionally, MCP-1 deficiency significantly reduced atherosclerosis in LDLR-deficient mice and human ApoB-expressing transgenic mice (Gu et al., 1998; Gosling et al., 1999), and the deletion of MCP-1 receptor (CCR2) markedly decreased atherosclerotic lesion formation in ApoE-deficient mice (Boring et al., 1998). It was also found that enhanced expression of MCP-1 by transplantation of MCP-1 overexpressing bone marrow cells accelerated atherosclerosis in ApoE-deficient mice (Aiello et al., 1999). Furthermore, patients with coronary artery disease had significantly elevated MCP-1 serum levels (Martinovic et al., 2005). Finally, anti-MCP-1 gene therapy successfully attenuated atherosclerosis in ApoEdeficient mice (Ni et al., 2001; Inoue et al., 2002), suggesting MCP-1 as a potential therapeutic target in atherosclerosis. These studies clearly demonstrate that MCP-1 plays a fundamental role in the pro-inflammatory pathways in vascular endothelium and serves as a contributing factor to atherosclerosis.

Rollins and Pober (1991) reported for the first time that IL-4 induced the synthesis of MCP-1 mRNA and secretion of MCP-1 protein by HUVEC. It was also found that treatment with IL-4 amplified the production of MCP-1 in TNF$\alpha$ - or IL-1-activated HUVEC (Colotta et al., 1992; Paleolog et al., 1992). In addition, recent studies by our group have demonstrated that IL-4 significantly up-regulates mRNA and protein expression of MCP-1 in vascular endothelium in vitro and in vivo (Lee et al., 2003; Lee et al., 2004b; Lee et al., 2010b). The functional integrity of MCP-1 induced by IL-4-treated human vascular endothelial cells was further verified by monocyte migration assay showing that the conditioned media collected from IL-4-activated HAEC significantly enhanced the migration of monocytes (Lee et al., 2010b).

\section{Effect of IL-4 on VCAM-1 expression in vascular endothe- lium}

Enhanced expression of adhesion molecules such as 
E-selectin, intercellular adhesion molecule-1 (ICAM-1) and VCAM-1 facilitates adherence of circulating blood leukocytes to vascular endothelium and their transendothelial migration which is directly linked to an early phase of atherosclerosis (Khan et al., 1995; Price and Loscalzo, 1999; Huo and Ley, 2001; Blankenberg et al., 2003). VCAM-1 is a member of the immunoglobulin gene superfamily first described as a cytokine-inducible endothelial adhesion protein (Osborn et al., 1989) and is expressed primarily on endothelial cells. Other cell types such as macrophages, myoblasts and dendritic cells are also capable of expressing VCAM-1 (Simmons et al., 1992; Barks et al., 1997; Blankenberg et al., 2003). It mediates cell-cell interactions via binding to its integrin counter receptor, integrin $\alpha 4 \beta 1$ or very late antigen-4 (VLA-4), which lead to the recruitment of mononuclear leukocytes to the vascular lesions in early atherosclerosis and the firm adhesion of blood leukocytes to the surface of vascular endothelium (Elices et al., 1990; Cybulsky and Gimbrone, 1991; Schleimer et al., 1992; Libby and Galis, 1995). Compelling evidence has indicated that VCAM-1 is one of the most important adhesion molecules involved in leukocyte infiltration to atherosclerotic lesions. Increased level of VCAM-1 expression has been detected on human arteries with atherosclerotic lesions (Davis et al., 1993; O'Brien et al., 1993) as well as on established lesions in animal models of atherosclerosis (Li et al., 1993; Sakai et al., 1997; Nakashima et al., 1998; liyama et al., 1999). In addition, blockade of VCAM-1 by monoclonal antibody abrogated monocyte adhesion on early atherosclerotic endothelium (Huo et al., 2000) and the monoclonal VCAM-1 antibody treatment inhibited neointimal formation after carotid artery injury in ApoE-deficient mice (Oguchi et al., 2000). Lumsden et al. (1997) also demonstrated that blocking VCAM-1/integrin $\alpha 4 \beta 1$ pathway by use of an anti-VLA-4 antibody significantly reduced the number of intimal macrophages, intimal cell proliferation, and intimal hyperplasia in injured carotid arteries in adult baboons. These data strongly support an important role of VCAM-1 in the development of atherosclerosis.

Several reports have indicated that IL-4 stimulates the adhesiveness of blood leukocytes to vascular endothelium via overexpression of VCAM-1. For example, enhanced VCAM-1 expression and adherence of peripheral blood lymphocytes on endothelial cells were observed in IL-4stimulated HUVEC (Galéa et al., 1992; Galéa et al., 1993). In addition, Masinovsky et al. (1990) demonstrated that IL-4 alone or in combination with IL-1 $\beta$ promoted lymphocyte binding to endothelium by induction of VCAM- 1 on microvascular endothelial cells. A significance increase in
VCAM-1 expression also mediated eosinophil adhesion on cultured human lung microvascular endothelial cells (HLMVEC) treated with IL-4 alone or combined with LPS (Blease et al., 1998). Moreover, treatment of HUVEC with IL-4 and TNF- $\alpha$ synergistically induced VCAM-1 expression which resulted in enhanced adhesiveness of HUVEC to T lymphocytes (Paleolog et al., 1992). Furthermore, we have demonstrated that IL-4 significantly and dose-dependently induces VCAM-1 expression in HUVEC and increases the adherence of human monocytes to HUVEC monolayer (Lee et al., 2001a; Lee et al., 2004b). Our most recent real-time reverse transcriptase-polymerase chain reaction (RT-PCR) analyses further confirmed a significant up-regulation of VCAM-1 expression in HAEC and mouse aortas (Unpublished data).

\section{OXIDATIVE MECHANISMS OF IL-4-INDUCED VASCULAR INFLAMMATION}

Cardiovascular risk factors increase reactive oxygen species (ROS) generation in vascular endothelium that plays an important role in the development of atherosclerosis (Hennig et al., 1996; Bouloumie et al., 1999). It has become apparent that endothelial dysfunction is closely associated with an increased risk of atherosclerosis and vascular endothelial cells are particularly sensitive to intracellular oxidative stress (Hennig and Chow, 1988; Thomas et al., 2008). In fact, enhanced production of superoxide anion was observed in human atherosclerotic coronary arteries (Sorescu et al., 2002; Guzik et al., 2006). Heitzer et al. (2001) also demonstrated that elevated production of vascular ROS was linked to impaired endothelial function and progression of atherosclerosis in patients with coronary artery disease. Additionally, oxidative stress up-regulates the expression of pro-inflammatory mediators such as cytokines, chemokines, and adhesion molecules in vascular endothelium, which is one of the earliest steps in the development of atherosclerotic lesion formation (Ylä-Herttuala, 1992; Ross, 1993; Bouloumie et al., 1999; Lee and Hirani, 2006).

\section{Involvement of ROS in IL-4-induced vascular inflamma- tion}

IL-4 may be considered a pro-oxidative cytokine which increases the oxidizing potential of target cells. For example, Park et al. (2008) reported that IL-4 induced oxidative stress in microglia and subsequently led to the death of hippocampal neurons in vivo. The crucial role of IL-4-induced oxidative stress in neurotoxicity was further confirmed by observations that IL-4 neutralizing antibody 
treatments significantly inhibited ROS generation and increased the survival of hippocampal neurons in rats (Park et al., 2008). In addition, the levels of the intracellular ROS were determined by dihydroethidium (DHE) and dichlorofluorescein (DCF) staining to examine whether IL-4 induces ROS generation in vascular endothelial cells. When DHE is oxidized to ethidium by superoxide anion, ethidium intercalates within the cell's DNA and stain its nucleus a bright fluorescent red. Dichlorofluorescin diacetate $\left(\mathrm{H}_{2} \mathrm{DCF}-\right.$ DA) is a stable, non-polar compound that readily diffuses into the cells and is converted to a non-fluorescent polar derivative dichlorofluorescin (DCF-H) by intracellular esterases. DCF-H is oxidized to the highly fluorescent compound DCF by hydrogen peroxide or other peroxides produced by the cells. The levels of DHE and DCF fluorescence were significantly increased after exposure of HUVEC (Lee et al., 2001a; Lee and Hirani, 2006; Walch et al., 2006) or HAEC (Lee et al., 2010a; Lee et al., 2010b) to IL-4, indicating that IL-4 treatment induces the generation of ROS such as superoxide anion and hydrogen peroxide in vascular endothelial cells. Effects of antioxidants on IL-4-induced expression of pro-inflammatory mediators have also been examined in endothelial cells. Pre-treatment with antioxidant such as pyrrolidine dithiocarbamate (PDTC), N-acetylcysteine (NAC) or epigallocatechin gallate (EGCG) resulted in a marked attenuation of IL-4-mediated overexpression of IL-6 (Lee et al., 2010a), MCP-1 (Lee et al., 2003; Walch et al., 2006; Lee et al., 2010b), and VCAM-1 (Lee et al., 2001a) in human vascular endothelial cells. These studies provide robust evidence that intracellular ROS generation is associated with IL-4-induced vascular inflammation.

\section{Effect of IL-4 on ROS-generating pathways and vascular inflammation}

Several distinct pathways generating ROS, including NADPH oxidase, xanthine oxidase, arachidonic acid metabolism, and mitochondrial electron transport chain (Fig. 1), are known to be involved in the signal transduction cascade of vascular inflammation and progression of atherosclerosis (Basta et al., 2005; Thomas et al., 2008). Recent in vitro and in vivo studies have described the intracellular sources of IL-4-induced ROS generation in vascular endothelium. NADPH oxidase (NOX) is a membrane-associated enzyme complex and catalyzes the transfer of electrons from NADPH to molecular oxygen to generate superoxide anion in vascular endothelium. It is a key source of enzymatic generation of ROS in a variety of cell types including endothelial cells (Brandes, 2003; Basta et al., 2005; Bedard and Krause, 2007; Thomas et al., 2008;

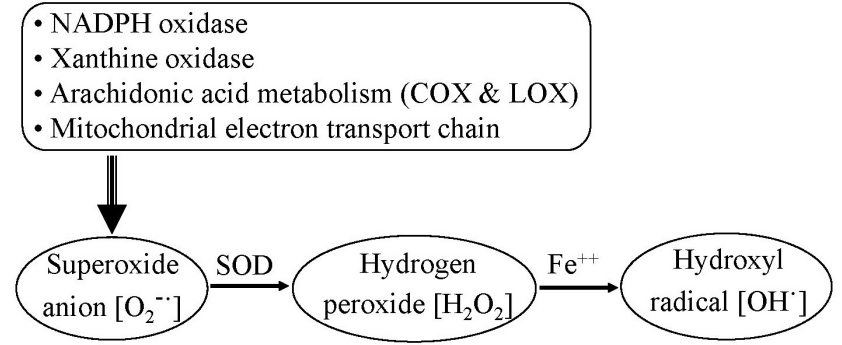

Fig. 1. Schematic diagram of pathways generating reactive oxygen species (ROS) in endothelial cells. COX: cyclooxygenase, LOX: lipoxygenase, SOD: superoxide dismutase.

Goettsch et al., 2009; Guzik and Griendling, 2009). Walch et al. (2006) demonstrated that gp91ds-tat, a selective NOX inhibitor, significantly attenuated ROS generation and MCP-1 overexpression in IL-4-stimulated HUVEC. Pre-treatment of HAEC with other NOX inhibitors such as apocynin and diphenylene iodonium (DPI) also markedly suppressed IL-4-induced ROS generation and overexpression of pro-inflammatory mediators such as IL-6 and MCP-1 (Lee et al., 2010a; Lee et al., 2010b). The crucial role of NOX-mediated ROS generation in IL-4-induced vascular inflammation was further confirmed by using NOX-2 knockout mice (NOX gp91 $1^{\text {phox-1- }}$ or B6.129S6-

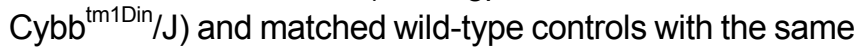
genetic background (C57BL/6J). The disruption of NOX-2 (NOX gp91 ${ }^{\text {phox }}$ ) gene markedly attenuated IL-4-induced IL-6 and MCP-1 expression in NOX-2 knockout mice (Lee et al., 2010a; Lee et al., 2010b). These studies provide robust evidence to suggest that NOX plays a pivotal role in ROS generation and overexpression of pro-inflammatory mediators in IL-4-stimulated vascular endothelium. Since NOX-2 was first discovered as a major innate immune defense mechanism, other homologues (e.g., NOX-1, NOX3 , NOX-4, NOX-5, Duox-1, and Duox-2), p22 $2^{\text {phox }}$, and several regulatory subunits (e.g., $\mathrm{p} 47^{\text {phox }}, \mathrm{p} 67^{\text {phox }}, \mathrm{p} 40^{\text {phox }}$, and rac proteins) have been identified in a variety of cells and tissues (Bedard and Krause, 2007; Thomas et al., 2008; Goettsch et al., 2009; Guzik and Griendling, 2009). Therefore, other NOX components may also be involved in IL-4-induced ROS generation in vascular endothelium and remain to be further investigated.

It has become increasingly apparent that metabolic pathways of arachidonic acid (AA) by several enzymes, including cyclooxygenase (COX) and lipoxygenase (LOX), are associated with the generation of ROS in vascular endothelium (Oltman et al., 2003; Thomas et al., 2008). Our recent findings suggest the potential involvement of $\mathrm{COX}$ and LOX in IL-4-induced ROS generation and vascular 
inflammation. Pre-treatment of HAEC with 5, 8, 11, 14-eicosatetraynoic acid (ETYA), a combined inhibitor of COX and LOX, or nordihydroguaiaretic acid (NDGA), a selective inhibitor of 5-LOX, significantly and dose-dependently attenuated IL-4-induced mRNA and protein expression of MCP-1, while N-2-(cyclohexyloxy)-4-nitrophenyl-methanesulfonamide (NS-398), a selective inhibitor of COX-2, did not exert any inhibitory effect (Unpublished data). Interestingly, none of these inhibitors had significant effects on IL-4-induced IL-6 expression in HAEC (Lee et al., 2010a). These results indicate that 5-LOX-mediated ROS generation may play a role in IL-4-induced vascular inflammation via MCP-1-dependent pathway.

Another enzymatic source of ROS generation in vascular endothelium is xanthine oxidase (XO). $X O$ is a form of xanthine oxidoreductase and produces ROS such as superoxide anion and hydrogen peroxide by catalyzing the metabolism of NADH, oxygen, and hypoxanthine/xanthine (Basta et al., 2005; Thomas et al., 2008). The contribution of XO-mediated ROS generation to pro-inflammatory pathways in IL-4-activated vascular endothelium was examined by pre-treatment of HAEC with allopurinol, an inhibitor of XO, which did not affect IL-4-mediated up-regulation of IL-6 (Lee et al., 2010a) and MCP-1 expression (Walch et al., 2006; Lee et al., 2010b). These studies indicate that $\mathrm{XO}$ is not associated with IL-4-mediated pro-oxidative and pro-inflammatory pathways in vascular endothelium.

It has been widely known that mitochondria generate ROS during normal respiration. Indeed, mitochondrial electron transport chain is one of the major sources of intracellular ROS production in vascular endothelium (Corda et al., 2001; Basta et al., 2005; Thomas et al., 2008). The role of mitochondrial electron transport chain in ROSmediated vascular inflammation in response to IL-4 was determined with various pharmacological inhibitors such as rotenone, thenoyltrifluoroacetone (TTFA), and antimycin A which selectively block the electron flows between mitochondrial respiratory chain complexes. Rotenone was employed as an inhibitor of complex I which blocks the electron flow from NADH dehydrogenase (complex I) to ubiquinone, TTFA as a complex II inhibitor which interferes with the electron transport from succinate dehydrogenase (complex II) to ubiquinone, and antimycin A as a selective inhibitor of the electron flow at complex III. Recent studies by our group and others demonstrated that inhibitions of mitochondrial electron transport chain did not exert any significant effects on IL-4-induced IL-6 (Lee et al., 2010a) and MCP-1 expression (Walch et al., 2006; Lee et al., $2010 \mathrm{~b}$ ) in human vascular endothelial cells. These results suggest that mitochondrial electron transport chain-mediated ROS generation is not involved in IL-4-induced expression of pro-inflammatory mediators in vascular endothelium.

\section{CONCLUSION}

Although IL-4 was traditionally believed to be an anti-inflammatory cytokine, a growing body of evidence from our group and others has raised possibility that IL-4 may play an important role in the initiation and progression of atherosclerosis via induction of oxidative stress and inflammation in vascular endothelium (Fig. 2).

Since atherosclerosis is a major public health problem and the exact cause of this disease remains unsolved, understanding the potential, novel pathophysiological mechanisms involved in atherogenesis is highly significant. Most previous in vivo and in vitro studies have exclusively implicated the Th1 cell-dependent mechanisms in this process. Therefore, the potential role for Th2 cell-dependent inflammatory responses will provide an excellent balance

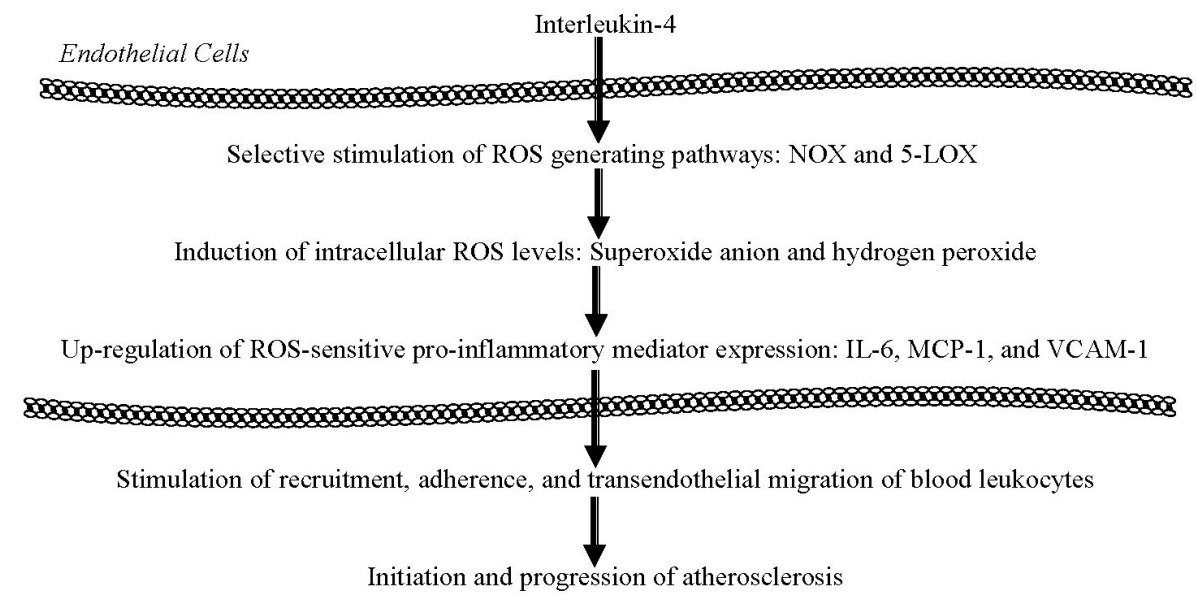

Fig. 2. Schematic diagram of the oxidative mechanisms of IL-4-induced vascular inflammation and development of atherosclerosis. ROS: reactive oxygen species, NOX: NADPH oxidase, 5-LOX: 5-lipoxygenase, IL-6: interleukin-6, MCP-1: monocyte chemoattractant protein-1, VCAM-1: vascular cell adhesion molecule-1. 
to the more extensive studies on Th1 cell responses in the pathophysiological processes of atherosclerosis. In addition, it will provide novel insights into a complex inflammatory process of atherosclerosis. A clear delineation of novel cellular and molecular signaling mechanisms by which IL-4, a Th2 cytokine, induces oxidative stress and inflammation in vascular endothelium will contribute to new early, preventative therapies for atherosclerosis.

\section{ACKNOWLEDGMENTS}

This study was supported in part by grants from National Institutes of Health/National Heart, Lung, and Blood Institute (HL085229) and National Science Foundation Macromolecular Interfaces with Life Sciences-Integrative Graduate Education and Research Traineeship (MILESIGERT).

\section{REFERENCES}

Aiello, R. J., Bourassa, P. K., Lindsey, S., Weng, W., Natoli, E., Rollins, B. J. and Milos, P. M. (1999). Monocyte chemoattractant protein-1 accelerates atherosclerosis in apolipoprotein E-deficient mice. Arterioscler. Thromb. Vasc. Biol. 19, 1518-1525.

American Heart Association Statistics Committee and Stroke Statistics Subcommittee. (2010). Heart disease and stroke statistics - 2010 update. Circulation 121, e1-e170.

Barks, J. L., McQuillan, J. J. and lademarco, F. (1997). TNF- $\alpha$ and IL-4 synergistically increase vascular cell adhesion molecule-1 expression in cultured vascular smooth muscle cells. J. Immunol. 159, 4532-4538.

Basta, G., Lazzerini, G., Del Turco, S., Ratto, G. M., Schmidt, A. M. and De Caterina, R. (2005). At least 2 distinct pathways generating reactive oxygen species mediate vascular cell adhesion molecule-1 induction by advanced glycation end products. Arterioscler. Thromb. Vasc. Biol. 25, 1401-1407.

Bedard, K. and Krause, K. (2007). The NOX family of ROSgenerating NADPH oxidase: Physiology and Pathophysiology. Physiol. Rev. 87, 245-313.

Berliner, J. A., Navab, M., Fogelman, A. M., Frank, J. S., Demer, L. L., Edwards, P. A., Watson, A. D. and Lusis, A. J. (1995). Atherosclerosis: basic mechanisms. Oxidation, inflammation, and genetics. Circulation 91, 2488-2496.

Blankenberg, S., Barbaux, S. and Tiret, L. (2003). Adhesion molecules and atherosclerosis. Atherosclerosis 170, 191203.

Blease, K., Seybold, J., Adcock, I. M., Hellewell, P. G. and Burke-Gaffney, A. (1998). Interleukin-4 and lipopolysaccharide synergize to induce vascular cell adhesion molecule-1 expression in human lung microvascular endothelial cells. Am. J. Respir. Cell Mol. Biol. 18, 620-630.

Boring, L., Gosling, J., Cleary, M. and Charo, I. F. (1998). Decreased lesion formation in CCR2 ${ }^{-1-}$ mice reveals a role for chemokines in the initiation of atherosclerosis. Nature 394, 894-897.
Bouloumie, A., Marumo, T., Lafontan, M. and Busse, R. (1999). Leptin induces oxidative stress in human endothelial cells. FASEB J. 13, 1231-1238.

Brandes, R. P. (2003). A radical adventure: The quest for specific functions and inhibitors of vascular NADPH oxidase. Circ. Res. 92, 583-585.

Braunersreuther, V., Mach, F. and Steffens, S. (2007). The specific role of chemokines in atherosclerosis. Thromb. Haemost. 97, 714-721.

Buono, C., Come, C. E., Stavrakis, G., Maguire, G. F., Connelly, P. W. and Lichtman, A. H. (2003). Influence of interferon- $\gamma$ on the extent and phenotype of diet-induced atherosclerosis in the LDLR-deficient mouse. Arterioscler. Thromb. Vasc. Biol. 23, 454-460.

Bursill, C. A., Channon, K. M. and Greaves, D. R. (2004). The role of chemokines in atherosclerosis: recent evidence from experimental models and population genetics. Curr. Opin. Lipidol. 15, 145-149.

Cesari, M., Penninx, B. W., Newman, A. B., Kritchevsky, S. B., Nicklas, B. J., Sutton-Tyrrell, K., Tracy, R. P., Rubin, S. M., Harris, T. B. and Pahor, M. (2003). Inflammatory markers and cardiovascular disease (The Health, Aging and Body Composition [Health ABC] Study). Am. J. Cardiol. 92, $522-528$

Chen, C. C. and Manning, A. M. (1996). TGF- $\beta 1$, IL-10 and IL-4 differentially modulate the cytokine-induced expression of IL-6 and IL-8 in human endothelial cells. Cytokine 8, 58-65.

Clark, L. T. (2002). Vascular inflammation as a therapeutic target for prevention of cardiovascular disease. Curr. Atheroscler. Rep. 4, 77-81.

Colotta, F., Sironi, M., Borre, A., Luini, W., Maddalena, F. and Mantovani, A. (1992). Interleukin 4 amplifies monocyte chemoattractant protein and interleukin 6 production by endothelial cells. Cytokine 4, 24-28.

Corda, S., Laplace, C., Vicaut, E. and Duranteau, J. (2001). Rapid reactive oxygen species production by mitochondria in endothelial cells exposed to tumor necrosis factor- $\alpha$ is mediated by ceramide. Am. J. Respir. Cell Mol. Biol. 24, 762-768.

Cybulsky, M. and Gimbrone, M. (1991). Endothelial expression of a mononuclear leukocyte adhesion molecule during atherogenesis. Science 251, 788-791.

Davenport, P. and Tipping, P. G. (2003). The role of interleukin-4 and interleukin-12 in the progression of atherosclerosis in apolipoprotein E-deficient mice. Am. J. Pathol. 163, 1117-1125.

Davies, M. J., Gordon, J. L., Gearing, A. J., Pigott, R., Woolf, N., Katz, D. and Kyriakopoulos, A. (1993). The expression of the adhesion molecules ICAM-1, VCAM-1, PECAM, and E-selectin in human atherosclerosis. J. Pathol. 171, 223229.

Elices, M., Osborn, L., Takada, Y., Crouse, C., Luhowskyj, S., Hemler, M. and Lobb, R. (1990). VCAM-1 on activated endothelium interacts with the leukocyte integrin VLA-4 at a site distinct from the VLA-4/fibronectin binding site. Cell 60, 577-584.

Galéa, P., Lebranchu, Y., Thibault, G. and Bardos, P. (1992). Interleukin 4 and tumor necrosis factor $\alpha$ induce different adhesion pathways in endothelial cells for the binding of peripheral blood lymphocytes. Scand. J. Immunol. 36, 575- 
585.

Galéa, P., Thibault, G., Lacord, M., Bardos, P. and Lebranchu $Y$. (1993). IL-4, but not tumor necrosis factor- $\alpha$, increases endothelial cell adhesiveness for lymphocytes by activating a cAMP-dependent pathway. J. Immunol. 151, 588-596.

Goettsch, C., Goettsch, W., Arsov, A., Hofbauer, L. C., Bornstein, S. R. and Morawietz, H. (2009). Long-term cyclic strain downregulates endothelial Nox4. Antioxid. Redox. Signal 11, 2385-2397.

Gosling, J., Slaymaker, S., Gu, L., Tseng, S., Zlot, C. H., Young, S. G., Rollins, B. J. and Charo, I. F. (1999). MCP-1 deficiency reduces susceptibility to atherosclerosis in mice that overexpress human apolipoprotein B. J. Clin. Invest. 103, 773-778.

Gu, L., Okada, Y., Clinton, S. K., Gerard, C., Sukhova, G. K., Libby, P. and Rollins, B. J. (1998). Absence of monocyte chemoattractant protein-1 reduces atherosclerosis in low density lipoprotein receptor-deficient mice. Mol. Cell 2 , 275-281.

Gu, L., Tseng, S. C. and Rollins, B. J. (1999). Monocyte chemoattractant protein-1. Chem. Immunol. 72, 7-29.

Guzik, T. J. and Griendling, K. K. (2009). NADPH oxidases: Molecular understanding finally reaching the clinical level? Antioxid. Redox. Signal 11, 2365-2370.

Guzik, T. J., Sadowski, J., Guzik, B., Jopek, A., Kapelak, B., Przybylowski, P., Wierzbicki, K., Korbut, R., Harrison, D. G. and Channon, K. M. (2006). Coronary artery superoxide production and nox isoform expression in human coronary artery disease. Arterioscler. Thromb. Vasc. Biol. 26, 333339.

Heitzer, T., Schlinzig, T., Krohn, K., Meinertz, T. and Munzel, T. (2001). Endothelial dysfunction, oxidative stress, and risk of cardiovascular events in patients with coronary artery disease. Circulation 104, 2673-2678.

Hennig, B. and Chow, C. K. (1988). Lipid peroxidation and endothelial cell injury: implication in atherosclerosis. Free Radical Biol. Med. 4, 99-106.

Hennig, B., Toborek, M., McClain, C. J. and Diana, J. N. (1996). Nutritional implications in vascular endothelial cell metabolism. J. Am. Coll. Nutr. 15, 345-358.

Hong, H. Y., Lee, H. Y., Kwak, W., Yoo, J., Na, M. H., So, I. S. Kwon, T. H., Park, H. S., Huh, S., Oh, G. T., Kwon, I. C., Kim, I. S. and Lee, B. H. (2008). Phage display selection of peptides that home to atherosclerotic plaques: IL-4 receptor as a candidate target in atherosclerosis. J. Cell. Mol. Med. 12, 2003-2014

Huang, H., Lavoie-Lamoureux, A. and Lavoie, J. P. (2009). Cholinergic stimulation attenuates the IL-4 induced expression of E-selectin and vascular endothelial growth factor by equine pulmonary artery endothelial cells. Vet. Immunol. Immunopharmacol. 132, 116-121.

Huang, H., Lavoie-Lamoureux, A., Moran, K. and Lavoie, J. P. (2007). IL-4 stimulates the expression of CXCL-8, E-selectin, VEGF, and inducible nitric oxide synthase mRNA by equine pulmonary artery endothelial cells. Am. J. Physiol. Lung Cell. Mol. Physiol. 292, L1147-L1154.

Huber, S. A., Sakkinen, P., Conze, D., Hardin, N. and Tracy, R. (1999). Interleukin-6 exacerbates early atherosclerosis in mice. Arterioscler. Thromb. Vasc. Biol. 19, 2364-2367.

Huo, Y., Hafezi-Moghadam, A. and Ley, K. (2000). Role of vascular cell adhesion molecule-1 and fibronectin connecting segment-1 in monocyte rolling and adhesion on early atherosclerotic lesions. Circ. Res. 87, 153-159.

Huo, Y. and Ley, K. (2001). Adhesion molecules and atherogenesis. Acta. Physiol. Scand. 173, 35-43.

liyama, K., Hajra, L., liyama, M., Li, H., DiChiara, M., Medoff, B. D. and Cybulsky, M. I. (1999). Patterns of vascular cell adhesion molecule-1 and intercellular adhesion molecule-1 expression in rabbit and mouse atherosclerotic lesions and at sites predisposed to lesion formation. Circ. Res. 85, 199-207.

Inoue, S., Egashira, K., Ni, W., Kitamoto, S., Usui, M., Otani, K. Ishibashi, M., Hiasa, K., Nishida, K. and Takeshita, A. (2002). Anti-monocyte chemoattractant protein-1 gene therapy limits progression and destabilization of established atherosclerosis in apolipoprotein E-knockout mice. Circulation 106, 2700-2706.

Khan, B. V., Parthasarathy, S. S., Alexander, R. W. and Medford, R. M. (1995). Modified low density lipoprotein and its constituents augment cytokine-activated vascular cell adhesion molecule-1 gene expression in human vascular endothelial cells. J. Clin. Invest. 95, 1262-1270.

King, V. L., Szilvassy, S. J. and Daugherty, A. (2002). Interleukin-4 deficiency decreases atherosclerotic lesion formation in a site-specific manner in female LDL receptor-/mice. Arterioscler. Thromb. Vasc. Biol. 22, 456-461.

Kirii, H., Niwa, T., Yamada, Y., Wada, H., Saito, K., Iwakura, Y., Asano, M., Moriwaki, H. and Seishima, M. (2003). Lack of interleukin-1 $\beta$ decreases the severity of atherosclerosis in ApoE-deficient mice. Arterioscler. Thromb. Vasc. Biol. 23, 656-660.

Kishikawa, H., Shimokama, T. and Watanabe, T. (1993). Localization of $\mathrm{T}$ lymphocytes and macrophages expressing IL-1, IL-2 receptor, IL-6 and TNF in human aortic intima: Role of cell mediated immunity in human atherogenesis. Virchows Arch. A. Pathol. Anat. Histopathol. 423, 433-442.

Kishimoto, T. (2005). Interleukin-6: From basic science to medicine-40 years in immunology. Annu. Rev. Immunol. 23, 1-21.

Lee, Y. W., Eum, S. Y., Chen, K. C., Hennig, B. and Toborek, M. (2004b). Gene expression profile in interleukin-4-stimulated human vascular endothelial cells. Mol. Med. 10, 19-27.

Lee, Y. W., Eum, S. Y., Nath, A. and Toborek, M. (2004a). Estrogen-mediated protection against HIV Tat proteininduced inflammatory pathways in human vascular endothelial cells. Cardiovasc. Res. 63, 139-148.

Lee, Y. W., Hennig, B. and Toborek, M. (2003). Redoxregulated mechanisms of IL-4-induced MCP-1 expression in human vascular endothelial cells. Am. J. Physiol. Heart Circ. Physiol. 284, H185-H192.

Lee, Y. W. and Hirani, A. A. (2006). Role of interleukin-4 in atherosclerosis. Arch. Pharm. Res. 29, 1-15.

Lee, Y. W., Kühn, H., Hennig, B., Neish, A. S. and Toborek, M. (2001a). IL-4-induced oxidative stress upregulates VCAM-1 gene expression in human endothelial cells. J. Mol. Cell. Cardiol. 33, 83-94.

Lee, Y. W., Kühn, H., Hennig, B. and Toborek, M. (2000). IL-4 induces apoptosis of endothelial cells through the caspase-3-dependent pathway. FBES Lett. 485, 122-126.

Lee, Y. W., Kühn, H., Kaiser, S., Hennig, B., Daugherty, A. and 
Toborek, M. (2001b). Interleukin-4 induces transcription of the 15-lipoxygenase-I gene in human endothelial cells. J. Lipid Res. 42, 783-791.

Lee, Y. W., Lee, W. H. and Kim, P. H. (2010a). Oxidative mechanisms of IL-4-induced IL-6 expression in vascular endothelium. Cytokine 49, 73-79.

Lee, Y. W., Lee, W. H. and Kim, P. H. (2010b). Role of NADPH oxidase in interleukin-4-induced monocyte chemoattractant protein-1 expression in vascular endothelium. Inflamm. Res. In press [DOI: 10.1007/s00011-010-0187-3].

Li, H., Cybulsky, M. I., Gimbrone, M. A. Jr. and Libby, P. (1993). An atherogenic diet rapidly induces VCAM-1, a cytokineregulatable mononuclear leukocyte adhesion molecule, in rabbit aortic endothelium. Arterioscler. Thromb. 13, 197204.

Libby, P. and Galis, Z. S. (1995). Cytokines regulate genes involved in atherogenesis. Ann. N. Y. Acad. Sci. 748, 158-168.

Libby, P., Ridker, P. M. and Maseri, A. (2002). Inflammation and atherosclerosis. Circulation 105, 1135-1143.

Lumsden, A. B., Chen, C., Hughes, J. D., Kelly, A. B., Hanson, S. R. and Harker, L. A. (1997). Anti-VLA-4 antibody reduces intimal hyperplasia in the endarterectomized carotid artery in nonhuman primates. J. Vasc. Surg. 26, 87-93.

Martinovic, I., Abegunewardene, N., Seul, M., Vosseler, M., Horstick, G., Buerke, M., Darius, H. and Lindemann, S. (2005). Elevated monocyte chemoattractant protein-1 serum levels in patients at risk for coronary artery disease. Circ. J. 69, 1484-1489.

Marx, N. and Grant, P. J. (2007). Endothelial dysfunction and cardiovascular disease - the lull before the storm. Diab. Vasc. Dis. Res. 4, 82-83.

Masinovsky, B., Urdal, D. and Gallatin, W. M. (1990). IL-4 acts synergistically with IL-1 $\beta$ to promote lymphocyte adhesion to microvascular endothelium by induction of vascular cell adhesion molecule-1. J. Immunol. 145, 2886-2895.

Nakashima, Y., Raines, E. W., Plump, A. S., Breslow, J. L. and Ross, R. (1998). Upregulation of VCAM-1 and ICAM-1 at atherosclerosis-prone sites on the endothelium in the ApoE-deficient mouse. Arterioscler. Thromb. Vasc. Biol. 18 842-851.

Nelken, N. A., Coughlin, S. R., Gordon, D. and Wilcox, J. N. (1991). Monocyte chemoattractant protein-1 in human atheromatous plaques. J. Clin. Invest. 88, 1121-1127.

Ni, W., Egashira, K., Kitamoto, S., Kataoka, C., Koyanagi, M., Inoue, S., Imaizumi, K., Akiyama, C., Nishida, K. I. and Takeshita, A. (2001). New anti-monocyte chemoattractant protein-1 gene therapy attenuates atherosclerosis in apolipoprotein E-knockout mice. Circulation 103, 2096-2101.

O'Brien, K. D., Allen, M. D., McDonald, T. O., Chait, A., Harlan, J. M., Fishbein, D., McCarty, J., Ferguson, M., Hudkins, K. and Benjamin, C. D. (1993). Vascular cell adhesion molecule-1 is expressed in human coronary atherosclerotic plaques. Implications for the mode of progression of advanced coronary atherosclerosis. J. Clin. Invest. 92, 945-951.

Oguchi, S., Dimayuga, P., Zhu, J., Chyu, K. Y., Yano, J., Shah, P. K., Nilsson, J. and Cercek, B. (2000). Monoclonal antibody against vascular cell adhesion molecule-1 inhibits neointimal formation after periadventitial carotid artery injury in genetically hypercholesterolemic mice. Arterioscler. Thro- mb. Vasc. Biol. 20, 1729-1736.

Ohta, H., Wada, H., Niwa, T., Kirii, H., Iwamoto, N., Fujii, H. Saito, K., Sekikawa, K. and Seisima, M. (2005). Disruption of tumor necrosis factor- $\alpha$ gene diminishes the development of atherosclerosis in ApoE-deficient mice. Atherosclerosis $\mathbf{1 8 0}$ 11-17.

Oltman, C. L., Kane, N. L., Miller, F. J. Jr., Spector, A. A., Weintraub, N. L. and Dellsperger, K. C. (2003). Reactive oxygen species mediate arachidonic acid-induced dilation in porcine coronary microvessels. Am. J. Physiol. Heart Circ. Physiol. 285, H2309-H2315.

Osborn, L., Hession, C., Tizard, R., Vassallo, C., Luhowskyj, S. Chi-Rosso, G. and Lobb, R. (1989). Direct expression cloning of vascular cell adhesion molecule 1, a cytokineinduced endothelial protein that binds to lymphocytes. Cell 59, 1203-1211.

Paleolog, E. M., Aluri, G. R. and Feldmann, M. (1992). Contrasting effects of interferon $\gamma$ and interleukin 4 on responses of human vascular endothelial cells to tumor necrosis factor $\alpha$. Cytokine 4, 470-478.

Park, K. W., Baik, H. H. and Jin, B. K. (2008). Interleukin-4-induced oxidative stress via microglial $\mathrm{NADPH}$ oxidase contributes to the death of hippocampal neurons in vivo. Curr. Aging Sci. 1, 192-201.

Paul, W. E. (1991). Interleukin-4: a prototypic immunoregulatory lymphokine. Blood 77, 1859-1870.

Price, D. T. and Loscalzo, J. (1999). Cellular adhesion molecules and atherogenesis. Am. J. Med. 107, 85-97.

Reape, T. J. and Groot, P. H. (1999). Chemokines and atherosclerosis. Atherosclerosis 147, 213 -225.

Ridker, P. M., Hennekens, C. H., Buring, J. E. and Rifai, N. (2000a). C-reactive protein and other markers of inflammation in the prediction of cardiovascular disease in women. $N$. Engl. J. Med. 342, 836-843.

Ridker, P. M., Rifai, N., Stampfer, M. J. and Hennekens, C. H. (2000b). Plasma concentration of interleukin-6 and the risk of future myocardial infarction among apparently healthy men. Circulation 101, 1767-1772.

Rocken, M., Racke, M. and Shevach, E. M. (1996). IL-4-induced immune deviation as antigen-specific therapy for inflammatory autoimmune disease. Immunol. Today 17, 225-231.

Rollins, B. J. (1997). Chemokines. Blood 90, 909-928.

Rollins, B. J. and Pober, J. S. (1991). Interleukin-4 induces the synthesis and secretion of MCP-1/JE by human endothelial cells. Am. J. Pathol. 138, 1315-1319.

Ross, R. (1993). The pathogenesis of atherosclerosis: a perspective for the 1990s. Nature 362, 801-809.

Ross, R. (1999). Atherosclerosis is an inflammatory disease. Am. Heart J. 138, S419-S420.

Sakai, A., Kume, N., Nishi, E., Tanoue, K., Miyasaka, M. and Kita, T. (1997). P-selectin and vascular cell adhesion molecule-1 are focally expressed in aortas of hypercholesterolemic rabbits before intimal accumulation of macrophages and T lymphocytes. Arterioscler. Thromb. Vasc. Biol. $17,310-316$

Schleimer, R. P., Sterbinsky, S. A., Kaiser, J., Bickel, C. A., Klunk, D. A., Tomioka, K., Newman, W., Luscinskas, F. W., Gimbrone, M. A. Jr. and Mclntyre, B. W. (1992). IL-4 induces adherence of human eosinophils and basophils but not neutrophils to endothelium. Association with expression of 
VCAM-1. J. Immunol. 148, 1086-1092.

Schuett, H., Luchtefeld, M., Grothusen, C., Grote, K. and Schieffer, B. (2009). How much is too much? Interleukin-6 and its signaling in atherosclerosis. Thromb. Haemost. 102, 215-222.

Seino, Y., Ikeda, U., Ikeda, M., Yamamoto, K., Misawa, Y., Hasegawa, T., Kano, S. and Shimada, K. (1994). Interleukin 6 gene transcripts are expressed in human atherosclerotic lesions. Cytokine 6, 87-91.

Sheikine, Y. A. and Hansson, G. K. (2006). Chemokines as potential therapeutic targets in atherosclerosis. Curr. Drug Targets 7, 13-27.

Shishehbor, M. H. and Bhatt, D. L. (2004). Inflammation and atherosclerosis. Curr. Atheroscler. Rep. 6, 131-139.

Simmons, P. J., Masinovsky, B., Longenecker, B. M., Berenson, R., Torok-Storb, B. and Gallatin, W. M. (1992). Vascular cell adhesion molecule-1 expressed by bone marrow stromal cells mediates the binding of hematopoietic progenitor cells. Blood 80, 388-395

Sorescu, D., Weiss, D., Lassegue, B., Clempus, R. E., Szocs, K., Sorescu, G. P., Valppu, L., Quinn, M. T., Lambeth, J. D., Vega, J. D., Taylor, W. R. and Griendling, K. K. (2002). Superoxide production and expression of Nox family proteins in human atherosclerosis. Circulation 105, 14291435.

Srinivasan, S., Hatley, M. E., Reilly, K. B., Danziger, E. C. and Hedrick, C. C. (2004). Modulation of PPAR $\alpha$ expression and inflammatory interleukin- 6 production by chronic glucose increases monocyte/endothelial adhesion. Arterioscler. Thromb. Vasc. Biol. 24, 851-857.

Strieter, R. M., Wiggins, R., Phan, S. H., Wharram, B. L., Showell, H. J., Remick, D. G., Chensue, S. W. and Kunkel, S. L. (1989). Monocyte chemotactic protein gene expression by cytokine-treated human fibroblasts and endothelial cells. Biochem. Biophys. Res. Commun. 162, 694-700.

Sukovich, D. A., Kauser, K., Shirley, F. D., DelVecchio, V., Halks-Miller, M. and Rubanyi, G. M. (1998). Expression of interleukin-6 in atherosclerotic lesions of male apoEknockout mice. Arterioscler. Thromb. Vasc. Biol. 18, 14981505.

Takeya, M., Yoshimura, T., Leonard, E. J. and Takahashi, K.
(1993). Detection of monocyte chemoattractant protein-1 in human atherosclerotic lesions by an anti-monocyte chemoattractant protein-1 monoclonal antibody. Hum. Pathol. 24, 534-539.

Taubman, M. B., Rollins, B. J., Poon, M., Marmur, J., Green, R. S., Berk, B. C. and Nadal-Ginard, B. (1992). JE mRNA accumulates rapidly in aortic injury and in platelet-derived growth factor-stimulated vascular smooth muscle cells. Circ. Res. 70, 314-325.

Tedgui, A. and Mallat, Z. (2006). Cytokines in atherosclerosis: pathogenic and regulatory pathways. Physiol. Rev. 86 515-581.

Thomas, S. R., Witting, P. K. and Drummond, G. R. (2008). Redox control of endothelial function and dysfunction: Molecular mechanisms and therapeutic opportunities. Antioxid. Redox Signal. 10, 1713-1765.

Toborek, M. and Kaiser, S. (1999). Endothelial cell functions Relationship to atherogenesis. Basic Res. Cardiol. 94, 295314.

Walch, L., Massade, L., Dufilho, M., Brunet, A. and Rendu, F. (2006). Pro-atherogenic effect of interleukin-4 in endothelial cells: modulation of oxidative stress, nitric oxide and monocyte chemoattractant protein-1 expression. Atherosclerosis 187, 285-291.

Weissenbach, M., Clahsen, T., Weber, C., Spitzer, D., Wirth, D., Vestweber, D., Heinrich, P. C. and Schaper, F. (2004). Interleukin-6 is a direct mediator of T cell migration. Eur. $J$. Immunol. 34, 2895-2906.

Wung, B. S., Cheng, J. J., Hsieh, H. J., Shyy, Y. J. and Wang, D. L. (1997). Cyclic strain-induced monocyte chemotactic protein-1 gene expression in endothelial cells involves reactive oxygen species activation of activator protein 1. Circ. Res. 81, 1-7.

Ylä-Herttuala, S. (1992). Gene expression in atherosclerotic lesions. Hertz 17, 270-276.

Ylä-Herttuala, S., Lipton, B. A., Rosenfeld, M. E., Sarkioja, T., Yoshimura, T., Leonard, E. J., Witztum, J. L. and Steinberg, D. (1991). Expression of monocyte chemoattractant protein 1 in macrophage-rich areas of human and rabbit atherosclerotic lesions. Proc. Natl. Acad. Sci. USA 88, 5252-5256. 